\title{
RM de encéfalo sin anestesia en pacientes recién nacidos. Experiencia inicial en Clínica Alemana de Santiago
}

\author{
Dres. Nicolás Sánchez $D^{(1)}$, María Francesca Castoldi $L^{(2)}$, Ximena Stecher $G^{(3)}$.
}

1. Fellow de Neurorradiología, Facultad de Medicina Clínica Alemana - Universidad del Desarrollo. Santiago - Chile.

2. Neurorradióloga, Clínica Alemana de Santiago. Facultad de Medicina Clínica Alemana - Universidad del Desarrollo. Santiago - Chile.

3. Neurorradióloga pediátrica. Clínica Alemana de Santiago. Facultad de Medicina Clínica Alemana - Universidad del Desarrollo. Santiago - Chile.

\section{Cerebral MRI performed without anesthesia in newborn (neonatal) patients. Initial experience in Clinica} Alemana of Santiago

\begin{abstract}
Introduction: Given that hypothermia cases have occurred in newborns after MRI with anesthesia and reproducing what was observed in centers visited overseas, we implemented a supervised protocol to evaluate the results of cerebral MRI performed without anesthesia or sedation in patients hospitalized in our institution. Objective: To display results of the protocol for performing cerebral MRI without anesthesia in our newborn patients. Materials and methods: A retrospective study, we evaluated cerebral MRI performed on newborns from September 2012 - July 2013. Protocol for performing MRI without anesthesia was applied in institutionalized patients. Variables are compared with MRI performed using anesthesia, during this period. Results: 22 cerebral MRI were performed, 14 without anesthesia. The duration of the study without anesthesia was 48 minutes on average, obtaining adequate images in 13 studies, reprogramming the examination with anesthesia in one case. Conclusions: The protocol implemented allows the acquisition of diagnosticquality cerebral MRI, obviating the anesthesia.
\end{abstract}

Keywords: Anesthesia, Cerebral, MRI, Newborns.

Resumen: Introducción: Dado casos de hipotermia en recién nacidos (RN) posterior a resonancia magnética (RM) con anestesia y reproduciendo lo observado en centros extranjeros visitados, implementamos protocolo supervisado para evaluar los resultados de RM encefálicas realizadas sin anestesia o sedación en pacientes hospitalizados en nuestra institución. Objetivo: Mostrar resultados del protocolo para realización de RM encefálica sin anestesia en nuestros pacientes RN. Materiales y métodos: Estudio retrospectivo, evaluamos RM encefálicas realizadas en RN entre septiembre 2012 - julio 2013. Se aplicó protocolo para realización de $R M$ sin anestesia en pacientes institucionalizados. Se comparan variables con RM realizadas con anestesia en ese periodo. Resultados: Se realizaron 22 RM encefálicas, 14 sin anestesia. La duración del estudio sin anestesia fue de 48 minutos promedio, obteniendo imágenes adecuadas en 13 estudios, reprogramando el examen con anestesia en un caso. Conclusiones: el protocolo implementado permite obtener RM encefálicas de calidad diagnóstica, obviando la anestesia.

Palabras clave: Anestesia, Encéfalo, Recién nacidos, Resonancia magnética.

Sánchez N, Castoldi MF, Stecher X. RM de encéfalo sin anestesia en pacientes recién nacidos. Experiencia inicial en Clínica Alemana de Santiago. Rev Chil Radiol 2014; 20(4): 143-148.

Correspondencia: Nicolás Sánchez D. I nicolassanchezd@gmail.com

Trabajo recibido el 20 de junio de 2014. Aceptado para publicación el 08 de septiembre de 2014.

\section{Introducción}

Cada vez se hace más necesario para los clínicos de las unidades de cuidados intensivos neonatales evaluar a sus pacientes recién nacidos $(R N)$ con estudios de imágenes para obtener un adecuado diagnóstico. La resonancia magnética $(\mathrm{RM})$ y la to- mografía computada (TC), están incluidas entre las distintas modalidades, en especial la primera para evitar el uso de radiaciones ionizantes y por su mayor sensibilidad en el diagnóstico de algunas patologías ${ }^{(1)}$.

Uno de los principales problemas al que nos enfrentamos en el estudio de estos pacientes es el 
artefacto de movimiento, que condiciona detrimento de la calidad del examen que muchas veces lo vuelve no diagnóstico. Por este motivo, los exámenes RM de pacientes $\mathrm{RN}$ consideran por defecto su realización bajo sedación o anestesia.

Sin embargo, cabe destacar que el uso de anestesia no está exento de riesgos ${ }^{(2)}$, entre los que se cuentan hipoxemia, hipotensión, rash cutáneo e, incluso, hipotermia ${ }^{(3)}$ y depresión respiratoria ${ }^{(1,4)}$. Se agregan, además, mayores costos económicos, secundarios a la utilización de instrumentos tecnológicos especializados, monitorización durante y posterior al procedimiento, así como la participación de un mayor contingente de personal de salud (equipo de anestesiología) ${ }^{(1)}$. Por último, la asociación de lo anteriormente descrito y el requerimiento de ayuno, que en algunos $\mathrm{RN}$ condiciona irritabilidad, disponen en modo negativo a los tratantes y a los padres y en cierto modo les dificulta la decisión de solicitar una $\mathrm{RM}$, que finalmente llevan a situaciones clínicas más críticas.

En el caso particular de nuestra experiencia, la presentación de un par de casos de hipotermia acentuada en pacientes $\mathrm{RN}$ después de la realización de RM con anestesia, nos llevó en conjunto con los clínicos a tomar medidas para reducir o evitar la presentación de nuevos eventos adversos asociados al uso de anestesia.

Para ello implementamos una preparación alternativa de estos pacientes, sin uso de sedación, a utilizar sólo en las RM de encéfalo practicadas a los menores de 30 días hospitalizados en nuestra institución y asegurando que las imágenes obtenidas cumplieran con el necesario requisito de adecuada calidad diagnóstica.

El objetivo de este trabajo es dar a conocer los resultados en su etapa inicial y el protocolo utilizado.

\section{Materiales y métodos}

Estudio retrospectivo en que se evalúan todas las RM de encéfalos realizadas en menores de 30 días (equipo GE HDX Sygna1.5T, protocolo estándar institucional de RM de encéfalo) entre septiembre 2012 y julio 2013, tomando en cuenta que el cambio en la preparación de los pacientes ocurre en septiembre 2012.

Se define el uso del protocolo sólo en los pacientes hospitalizados en nuestra institución. Se excluyeron los exámenes solicitados a RN de otros hospitales, a los que se prefirió seguir estudiando bajo anestesia, para evitar reagendamientos por los consiguientes mayores costos y retraso en el diagnóstico que ello habría implicado.

Se acuerdan todos los puntos con los neonatólogos y se informa a los anestesiólogos, que inicialmente nos dan un soporte presencial para mayor seguridad. Se les solicita a los tratantes que en cada caso se informe bien a los padres sobre las condiciones del examen por si fuera necesario reprogramar bajo anestesia. El protocolo de preparación definido consiste en:

1. Alimentación con leche materna/fórmula aproximadamente 30 minutos antes del examen con el objeto de que el RN se duerma.

2. Inmovilización suave envolviendo al paciente con una manta (Figura 1) previa instalación de tapones en los oídos.

3. Posicionamiento en la camilla de RM, fijando la cabeza con almohadillas en el interior de la bobina de superficie (Figura 2), en una posición que parezca cómoda para el paciente.

4. Monitorización con oximetría de pulso y presencia durante todo el examen de la enfermera o el pediatra tratantes con permanencia de ellos al interior de la sala de RM realizando supervisión directa del paciente y sus signos vitales.

5. Supervisión estrecha de las imágenes obtenidas por un neurorradiólogo.

6. En caso de que no se logren imágenes diagnósticas, el examen deberá ser reprogramado bajo anestesia.

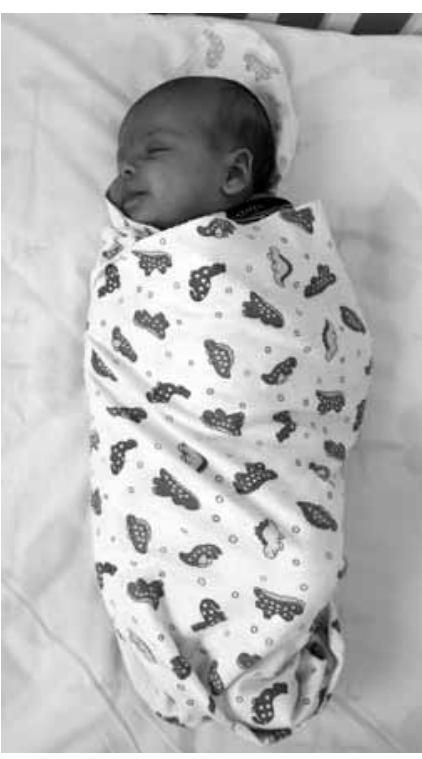

Figura 1. $R N$ inmovilizado suavemente con manta previo a estudio de $R M$ de encéfalo sin anestesia.

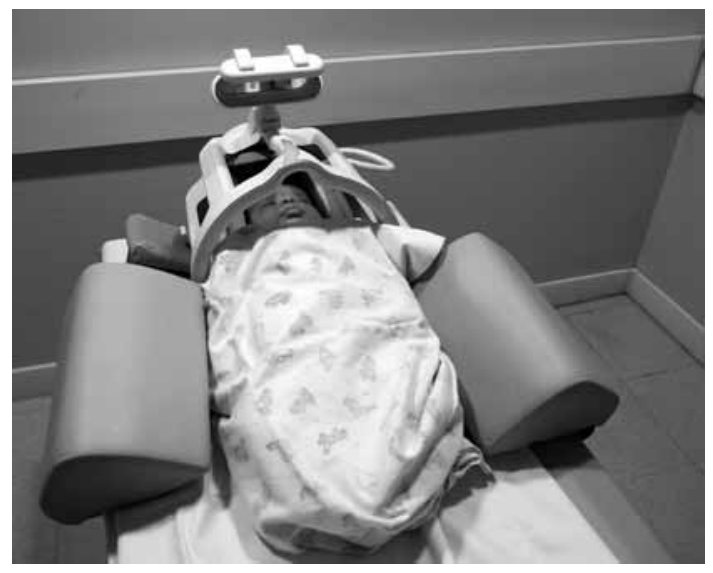

Figura 2. $R N$ posicionado en bobina previo al estudio de RM de encéfalo sin anestesia. 
Se analizaron distintas variables como edad gestacional, edad de nacido en días, tiempo de resonador, obtención de imágenes diagnósticas, repetición de secuencias (incluyendo localizadores) y necesidad de reprogramar el estudio con anestesia, comparando contra los resultados de las RM de encéfalo de RN realizadas con anestesia durante el mismo periodo, en pacientes derivados de otras instituciones o de aquellos institucionales que requirieran anestesia puesto que además tenían otros estudios en el mismo evento.

\section{Resultados}

Entre septiembre de 2012 y junio de 2013 se realizaron un total de $23 \mathrm{RM}$ de encéfalo en $\mathrm{RN}, 9$ con anestesia. De estas últimas, 6 fueron a pacientes derivados de otras instituciones de salud, y de los pacientes restantes, institucionales, uno requería una
RM de abdomen en el mismo evento y el otro estaba conectado a ventilación mecánica.

Las características de los pacientes de los grupos no anestesiados y los sometidos a anestesia se muestran en las tablas I, II y III.

Los exámenes realizados sin anestesia no utilizaron contraste IV en consideración a los diagnósticos presuntos y a que lo hallazgos tampoco lo justificaron y duraron una mediana de 39 minutos (desde $15 \mathrm{y}$ hasta 118 minutos, promedio de 48 minutos). Los estudios realizados con anestesia tuvieron una mediana de duración de 30 minutos (desde 20 y hasta 44 minutos, promedio de 29 minutos), sin considerar las secuencias contrastadas, realizadas en 7 de los pacientes anestesiados, alcanzando en este caso una mediana de duración de 42 minutos (desde 20 hasta 77 minutos, promedio de 45 minutos) (Tabla IV). Cabe comentar que la mayoría de los neurorradiólogos de

\begin{tabular}{|c|c|c|c|c|c|c|c|c|}
\hline Paciente & Sexo & $\begin{array}{l}\text { Edad } \\
\text { gestacional } \\
\text { (semanas) }\end{array}$ & $\begin{array}{l}\text { Edad } \\
\text { en RM } \\
\text { (días) }\end{array}$ & $\begin{array}{l}\text { Peso } \\
\text { (gramos) }\end{array}$ & $\begin{array}{l}\text { Tiempo total } \\
\text { de RM } \\
\text { (minutos } \\
\text { aprox) }\end{array}$ & $\begin{array}{l}\text { Tiempo total } \\
\text { de RM sin } \\
\text { contraste } \\
\text { (minutos } \\
\text { aprox) }\end{array}$ & $\begin{array}{l}\text { № secuencias } \\
\text { realizadas } \\
\text { (incluye } \\
\text { localizadores) }\end{array}$ & $\begin{array}{l}\text { № secuencias } \\
\text { repetidas } \\
\text { (incluye } \\
\text { localizadores) }\end{array}$ \\
\hline $\mathrm{RN} 1$ & $\mathrm{~F}$ & 39 & 1 & 2930 & 36 & 36 & 15 & 6 \\
\hline $\mathrm{RN} 2$ & $\mathrm{~F}$ & 37 & 1 & 2950 & 23 & 23 & 11 & 2 \\
\hline RN 3 & $M$ & 38 & 1 & 3140 & 39 & 39 & 20 & 10 \\
\hline $\mathrm{RN} 4$ & $\mathrm{~F}$ & 38 & 1 & 3258 & 39 & 39 & 20 & 9 \\
\hline RN 5 & $\mathrm{~F}$ & 37 & 4 & 1974 & 46 & 46 & 18 & 10 \\
\hline RN 6 & $\mathrm{~F}$ & 39 & 5 & 3359 & 55 & 55 & 23 & 13 \\
\hline RN 7 & $\mathrm{~F}$ & 35 & 6 & 2292 & 36 & 36 & 13 & 3 \\
\hline RN 8 & $M$ & 36 & 6 & 3870 & 32 & 32 & 12 & 2 \\
\hline RN 9 & $\mathrm{~F}$ & 40 & 7 & 4022 & 118 & $\begin{array}{c}118 \\
\text { (pausa de } 90 \mathrm{~min} \text { ) }\end{array}$ & $\begin{array}{c}12 \\
\text { (pausa de } 90 \mathrm{~min} \text { ) }\end{array}$ & 2 \\
\hline RN 10 & M & 39 & 7 & 3501 & 15 & 15 & 11 & 3 \\
\hline RN 11 & $\mathrm{~F}$ & 35 & 13 & 2755 & 42 & 42 & 14 & 6 \\
\hline RN 12 & M & 36 & 14 & 2290 & 95 & $\begin{array}{c}95 \\
\text { (pausa } 37 \mathrm{~min} \text { ) }\end{array}$ & $\begin{array}{c}18 \\
\text { (pausa } 37 \mathrm{~min} \text { ) }\end{array}$ & 8 \\
\hline RN 13 & $M$ & 33 & 15 & 1990 & 58 & 58 & 23 & 13 \\
\hline RN 14 & M & 37 & 1 & 2140 & $\begin{array}{c}\text { paciente } \\
\text { reprogramado } \\
\text { para anestesia }\end{array}$ & & & \\
\hline
\end{tabular}

\begin{tabular}{|c|c|c|c|c|c|c|c|c|}
\hline Paciente & Sexo & $\begin{array}{l}\text { Edad } \\
\text { gestacional } \\
\text { (semanas) }\end{array}$ & $\begin{array}{l}\text { Edad } \\
\text { en RM } \\
\text { (días) }\end{array}$ & $\begin{array}{l}\text { Peso } \\
\text { (gramos) }\end{array}$ & $\begin{array}{l}\text { Tiempo total } \\
\text { de RM } \\
\text { (minutos } \\
\text { aprox) }\end{array}$ & $\begin{array}{l}\text { Tiempo total } \\
\text { de RM sin } \\
\text { contraste } \\
\text { (minutos } \\
\text { aprox) }\end{array}$ & $\begin{array}{l}\text { № secuencias } \\
\text { realizadas } \\
\text { (incluye } \\
\text { localizadores) }\end{array}$ & $\begin{array}{l}\text { № secuencias } \\
\text { repetidas } \\
\text { (incluye } \\
\text { localizadores) }\end{array}$ \\
\hline RN 1 & $\mathrm{M}$ & 37 & 8 & 3590 & 49 & 38 & 14 & 2 \\
\hline RN 2 & $\mathrm{~F}$ & 38 & 20 & 3900 & 37 & 25 & 15 & 1 \\
\hline $\mathrm{RN} 3$ & $\mathrm{M}$ & 36 & 20 & 2880 & 57 & 44 & 19 & 1 \\
\hline RN 4 & $\mathrm{~F}$ & 39 & 26 & 4025 & 37 & 30 & 12 & 0 \\
\hline RN 5 & $\mathrm{~F}$ & 38 & 27 & 4200 & 56 & 18 & 14 & 0 \\
\hline RN 6 & $\mathrm{~F}$ & 39 & 28 & 2950 & 77 & 34 & 21 & 7 \\
\hline RN 7 & $\mathrm{~F}$ & 38 & 30 & 2668 & 20 & 20 & 10 & 2 \\
\hline RN 8 & $M$ & 35 & 29 & $x$ & 42 & 32 & 14 & 1 \\
\hline $\mathrm{RN} 9^{*}$ & $\mathrm{M}$ & 37 & 1 & 2140 & 30 & 22 & 8 & 0 \\
\hline
\end{tabular}


Tabla III. Comparación datos demográficos de los dos grupos de pacientes. Datos demográficos de los dos grupos de pacientes.

$$
\text { RM sin anestesia }(n=14) \quad R M \text { con anestesia }(n=9)
$$

\begin{tabular}{|c|c|c|c|}
\hline \multicolumn{2}{|c|}{$\begin{array}{l}\text { Edad gestacional al } \\
\text { nacimiento }\end{array}$} & 37 semanas $^{*}(33-40)$ & 38 semanas $^{*}(35-39)$ \\
\hline \multicolumn{2}{|c|}{ Edad en RM } & 5,5 días ${ }^{*}(1-15)$ & 26 días* $(1-30)^{*}$ \\
\hline Sexo & $\begin{array}{l}\text { Masculino } \\
\text { Femenino }\end{array}$ & $\begin{array}{l}6 \\
8\end{array}$ & $\begin{array}{l}4 \\
5\end{array}$ \\
\hline $\begin{array}{l}\text { Peso } \\
\text { *mediana }\end{array}$ & & $\begin{array}{l}2.940 \text { gramos }^{*} \\
\text { Rango: } 1974-3870\end{array}$ & $\begin{array}{c}3.270 \text { gramos }^{*} \\
\text { Rango: } 2140-4200\end{array}$ \\
\hline
\end{tabular}

Tabla IV. Comparación de duración y número de secuencias realizadas en los estudios de RM encefálica en los dos grupos. Comparación de duración y número de secuencias de RM de encéfalo.

\begin{tabular}{|c|c|c|}
\hline & RM $\sin$ anestesia $(n=14)$ & RM con anestesia $(n=9)$ \\
\hline Tiempo total de estudio & $\begin{array}{l}39 \text { minutos }^{*} \text { (desde } 15 \\
\text { hasta } 118 \text { minutos) } \\
\text { promedio: } 48 \text { minutos }\end{array}$ & $\begin{array}{l}42 \text { minutos }^{*} \text { (desde } 20 \\
\text { hasta } 77 \text { minutos) } \\
\text { promedio: } 45 \text { minutos }\end{array}$ \\
\hline $\begin{array}{l}\text { Tiempo de estudio sin } \\
\text { secuencias contrastadas }\end{array}$ & $\begin{array}{l}39 \text { minutos }^{*} \text { (desde } 15 \\
\text { hasta } 118 \text { minutos) } \\
\text { promedio: } 48 \text { minutos }\end{array}$ & $\begin{array}{l}30 \text { minutos }^{*} \text { (desde } 20 \\
\text { hasta } 44 \text { minutos) } \\
\text { promedio: } 29 \text { minutos }\end{array}$ \\
\hline $\begin{array}{l}\text { № secuencias realizadas } \\
\text { sin contraste } \\
\text { (incluye localizadores) }\end{array}$ & $15^{\star}(9-21)$ & $12^{*}(8-19)$ \\
\hline $\begin{array}{l}\text { № secuencias realizadas } \\
\text { incluyendo contraste } \\
\text { (incluye localizadores) }\end{array}$ & $15^{*}(9-21)$ & $14^{*}(10-21)$ \\
\hline $\begin{array}{l}\text { № secuencias repetidas } \\
\text { (incluye localizadores) }\end{array}$ & $6^{*}(2-13)$ & $1^{*}(0-7)$ \\
\hline * = mediana & & \\
\hline
\end{tabular}

nuestro equipo tiene la política de administrar contraste IV en los estudios bajo anestesia para mayor seguridad.

En los estudios realizados sin anestesia fue necesario repetir un mayor número de secuencias debido a artefactos de movimiento, repitiéndose como promedio 6 secuencias por paciente (entre 2 y 13 secuencias, mediana 6), mientras que en los estudios con anestesia se repitieron como promedio 1,6 secuencia (entre 0 y 7 secuencias, mediana 1) (Tabla IV). En dos estudios sin anestesia se optó por detener el estudio, sacar al paciente, realimentarlo y dormirlo, y reiniciarlo después de una pausa, por lo que estos exámenes duraron 37 y 91 minutos cada uno. Se reprogramó para la realización bajo anestesia sólo uno de los estudios puesto que las imágenes obtenidas no se consideraron diagnósticas. Los datos de este nuevo examen fueron incluidos en el grupo de los RN anestesiados.

No se incluyen en esta evaluación los tiempos utilizados en la preparación anestésica, en los casos que se usó, que implican uso de la sala de RM puesto que se realiza al interior de ella en el caso de los niños, para añadir ese tiempo al de la toma del examen mismo y comparar vs el mayor tiempo que implicó la repetición de secuencias en los estudios sin anestesia.

\section{Discusión}

La realización de estudios de imágenes de RM encefálica es una necesidad clínica creciente en los servicios de neonatología, y por las características 
de estos pacientes y simplificación de flujos se considera necesario el uso de sedación o anestesia. Sin embargo, estos últimos procedimientos tienen riesgos médicos asociados, determinan aumento del costo del examen y mayor sobrecarga de trabajo para el equipo de anestesiología, y requieren ayuno, todo lo cual a su vez desmotiva a los tratantes y a los padres para tomar la decisión de realizar una RM con mayor libertad.

Por lo tanto, se hace necesario diseñar o reproducir conductas que mejoren esas condiciones negativas sin detrimento de otras consideraciones de la atención, o que el detrimento, por ejemplo, en mayores tiempos consumidos sea menor que la mejora obtenida y percibida por los tratantes, los padres y nosotros mismos, en los resultados en calidad y seguridad entregados a nuestros pacientes ${ }^{(5)}$.

Es importante tener en cuenta que la utilización de este protocolo de estudio que considera alimentación previa al examen e inmovilización con mantas (que además evitan el enfriamiento del RN), obliga a repetir secuencias, requiere que exista personal tratante acompañando a los RN directamente y que los radiólogos estén supervisando en forma constante las imágenes obtenidas, para asegurar la obtención de un estudio con calidad diagnóstica.

Sin embargo, los resultados iniciales nos indican, al igual que lo descrito en la literatura ${ }^{(5,6)}$ que podemos prescindir del uso de anestesia para la RM de encéfalo en $\mathrm{RN}$, obteniendo imágenes de calidad diagnóstica (Figuras 3 y 4).

A partir de estos resultados alentadores nuestra idea es mejorar la captura de datos en los futuros exámenes en forma prospectiva, para evaluar con más detalle los distintos factores que pueden contribuir al éxito o fracaso de los procedimientos sin anestesia y a mejorar la selección de los pacientes para asegurar el buen resultado.

Un elemento que creemos muy relevante es la edad de los pacientes, puesto que, si bien incluimos pacientes hasta 30 días, en esta evaluación todos tuvieron menos de 15 días y es posible que los resultados sean distintos en la medida que el $\mathrm{RN}$ es mayor.

En el mercado extranjero se venden distintas alternativas de bolsas o sacos para inmovilizar a los RN para la realización de las RM ("vacuum infant inmobilizer bag") $)^{(1,5,6)}$, si bien no las consideramos imprescindibles para iniciar esta experiencia, podría considerarse su adquisición y uso para ver si mejoran los resultados.

Así mismo, existen otras modalidades alternativas no farmacológicas para tranquilizar y dormir a los pacientes o para el manejo del dolor en pediatría. Entre ellas la administración vía oral o enteral ya sea de sacarosa (sucrosa) o de glucosa concentrada ${ }^{(7,8)}$. Lo bueno de esta técnica es que en caso que el paciente se mueva no habría contraindicación para

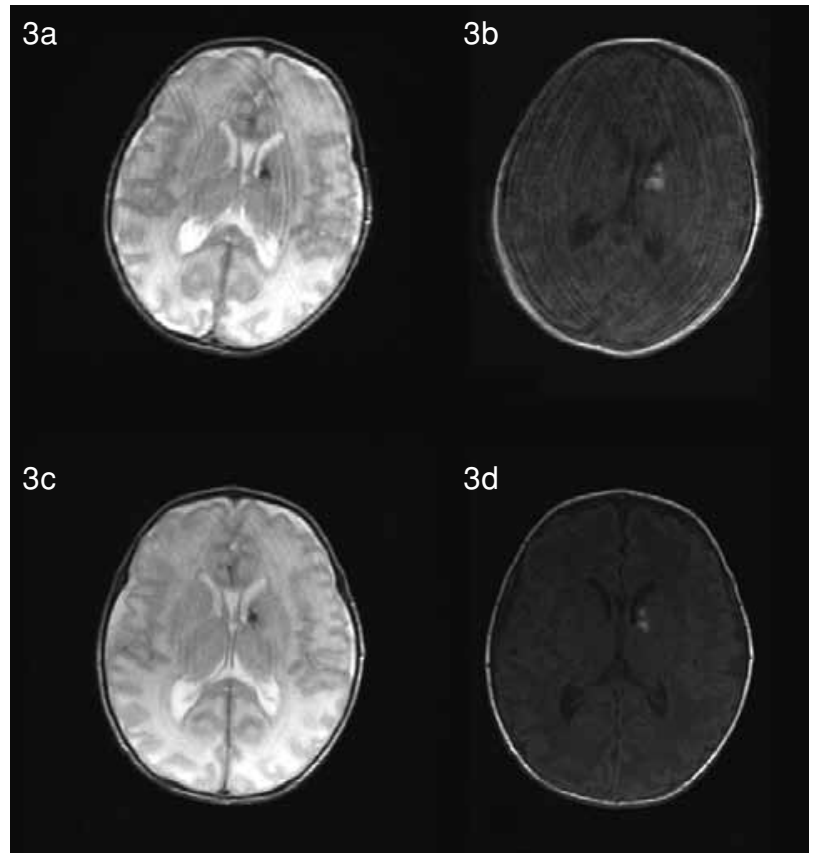

Figura 3. $R M$ de encéfalo en $R N$ sin anestesia. Secuencias axial T2 (a), axial T1 (b), axial T2 PROPELLER (c) y axial T1 propeller (d) del mismo paciente. Se identifica hemorragia del surco caudotalámico, claramente visible en las cuatro secuencias, sin embargo, destaca que el uso de secuencias propeller disminuye los artefactos de movimiento de la imagen.

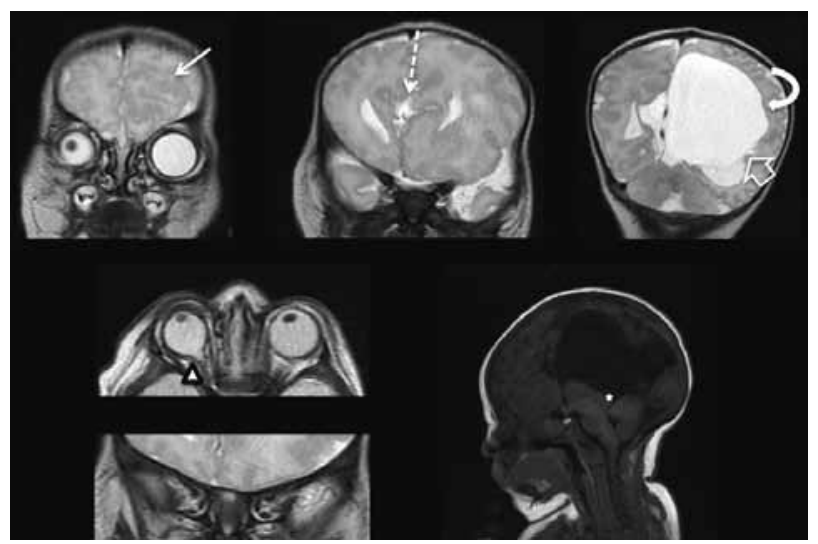

Figura 4. RM de encéfalo en $R N$ sin anestesia. A pesar de no usar anestesia se obtienen imágenes de calidad que nos permiten identificar múltiples alteraciones, como polimicrogiria frontal (flecha sólida), asimetría de los hemisferios cerebrales, agenesia del cuerpo calloso (flecha punteada), quiste interhemisférico (flecha curva), nódulos heterotópicos subependimarios (flecha hueca), engrosamiento de la placa tectal $\left({ }^{*}\right)$, displasia cerebelosa, coloboma ojo derecho (punta de flecha) e hipoplasia de nervios ópticos. Hallazgos compatibles con un síndrome de Aicardi. 
administrar la anestesia en el mismo evento. Sin embargo, nosotros no la hemos puesto en práctica para realizar las RM.

\section{Bibliografía}

1. Haney B, Reavey D, Atchison L, Poull J, et al. Magnetic Resonance Imaging Studies Without Sedation in the Neonatal Intensive Care Unit: Safe and Efficient. J Perinat Neonatal Nurs 2010; 24(3): 256-266.

2. Malviya S, Voepel-Lewis T, Eldevik O, Rocwell D, Wong J, Tait A. Sedation and general anaesthesia in children undergoing MRI and CT: adverse events and outcomes. Br J Anaesth 2000; 84(6): 743-748.

3. Witt L, Dennhardt N, Eich C, Mader T, Fischer T, Bräuer $A$ et al. Prevention of intraoperative hypothermia in neonates and infants: results of a prospective multicenter observational study with a new forced-air warming system with increased warm air flow. Pediatr Anesth 2013; 23(6): 469-474.
4. Shankar VR. Sedating children for radiological procedures: an intensivist's perspective. Pediatr Radiol 2008; 38 (Suppl 2): 213-217.

5. Golan A, Marco R, Raz H, Shany E. Imaging in the Newborn: Infant Immobilizer Obviates the Need for Anesthesia. Isr Med Assoc J 2011; 13(11): 663-665.

6. Mathur AM, Neil JJ, McKinstry RC, Inder TE. Transport, monitoring and successful brain MR imaging in unsedated neonates. Pediatr Radiol 2008; 38(3): 260-264.

7. American Academy of Pediatrics Committee on Fetus and Newborn; American Academy of Pediatrics Section on Surgery; Canadian Paediatric Society Fetus and Newborn Committee, Batton DG, Barrington KJ, Wallman C. Prevention and Management of Pain: An Update. Pediatrics 2006; 118(5): 2231-2241.

8. Marcatto JD, Tavares EC, Silva YP. Benefits and limitations of the use of glucose for the treatment of pain in neonates: a literature review. Rev Bras Ter Intensiva 2011; 23(2): 228-237.

\section{Tecnología superior para el diagnóstico e informe remoto}
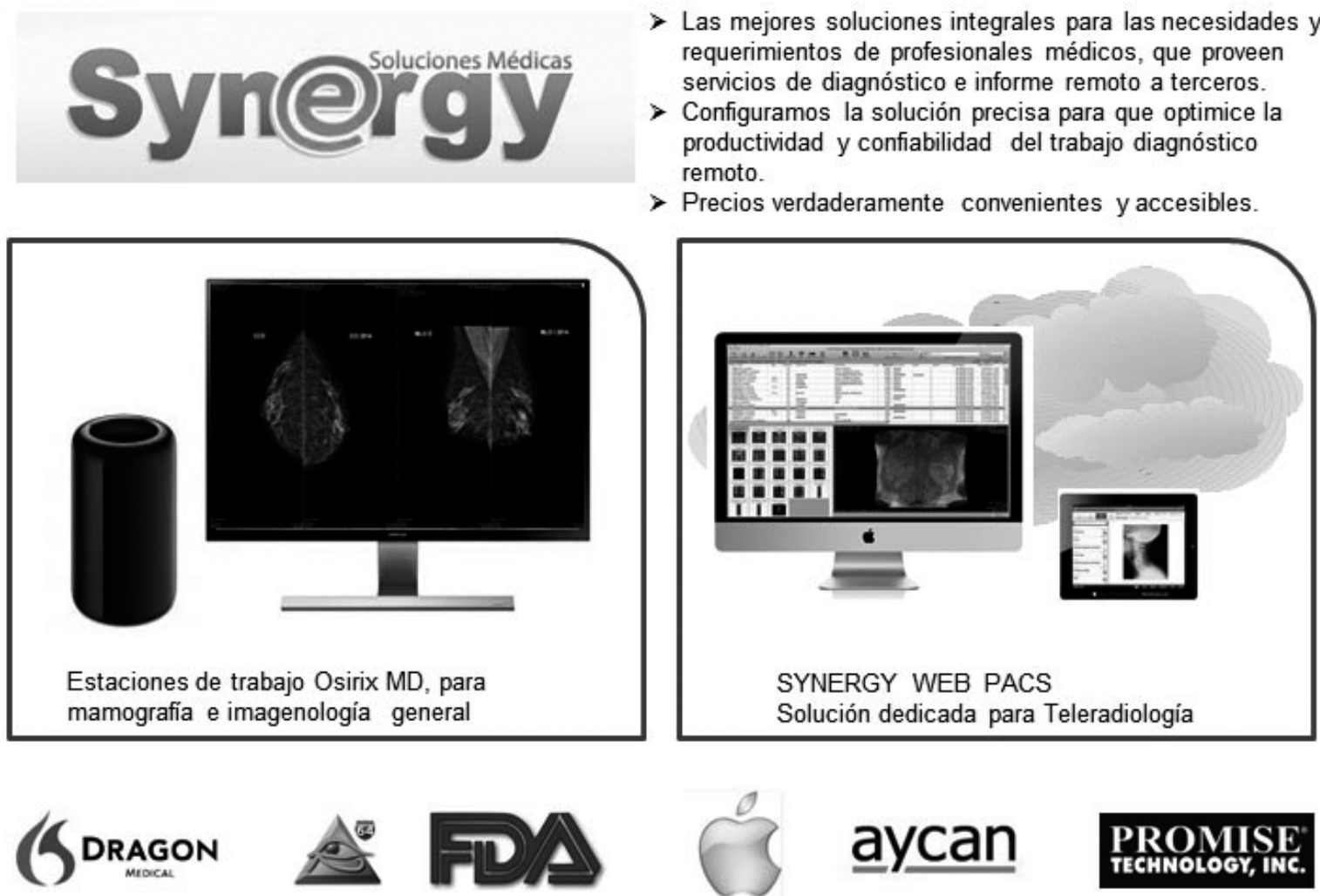

Synergy S.A. - Alférez Real 1154, Providencia-Santiago Tel: +562 28987400 - Fax. +56228987401-consultas@synergy.cl 